\title{
Spatial quantum correlations induced by random multiple scattering of quadrature squeezed light
}

\author{
Lodahl, Peter
}

Published in:

Conference on Lasers and Electro-Optics Europe

Link to article, DOI:

10.1109/CLEOE-IQEC.2007.4386881

Publication date:

2007

Document Version

Publisher's PDF, also known as Version of record

Link back to DTU Orbit

Citation (APA):

Lodahl, P. (2007). Spatial quantum correlations induced by random multiple scattering of quadrature squeezed light. In Conference on Lasers and Electro-Optics Europe (pp. 1-1). IEEE. https://doi.org/10.1109/CLEOEIQEC.2007.4386881

\section{General rights}

Copyright and moral rights for the publications made accessible in the public portal are retained by the authors and/or other copyright owners and it is a condition of accessing publications that users recognise and abide by the legal requirements associated with these rights.

- Users may download and print one copy of any publication from the public portal for the purpose of private study or research.

- You may not further distribute the material or use it for any profit-making activity or commercial gain

- You may freely distribute the URL identifying the publication in the public portal 


\title{
Spatial Quantum Correlations Induced by Random Multiple Scattering of Quadrature Squeezed Light
}

\author{
Peter Lodahl \\ COM•DTU Department of Communications, Optics, and Materials, Nano $D T U$, Technical University of Denmark
}

DTU - Building 345V, DK-2800 Kgs. Lyngby, Denmark, e-mail: pel@com.dtu.dk

Multiple scattering of light is an interdisciplinary research field that connects traditionally remote areas such as optical communication or biomedical imaging to fundamental physics studies of Anderson localization of light. In most work on multiple scattering a classical description of both light and matter is sufficient. In contrast, quantum optics studies of multiple scattering, where light is quantized, have only been initiated recently. A surprisingly rich variety of new phenomena is encountered in the quantum optics theory, including the identification of spatial [1] and frequency [2] quantum correlations induced by multiple scattering of Fock states.

Here we demonstrate that spatial quantum correlations are induced by multiple scattering of quadrature squeezed light through a random medium. As a consequence, light scattered along two different directions by the random medium will not be independent, but be correlated to an extent that can only be described by a quantum mechanical theory for multiple scattering. The spatial quantum correlation is revealed in the fluctuations of the total intensity transmission or reflection through the multiple scattering medium, see Figure 1. In contrast, only excess fluctuations, and no spatial correlations, appear if quadrature amplitudes would be measured. Quadrature squeezing is routinely generated by nonlinear frequency conversion such as second-harmonic generation or parametric oscillations. It is demonstrated that the spatial quantum correlations should be observable for realistic values of amplitude squeezing and scattering parameters of the medium.
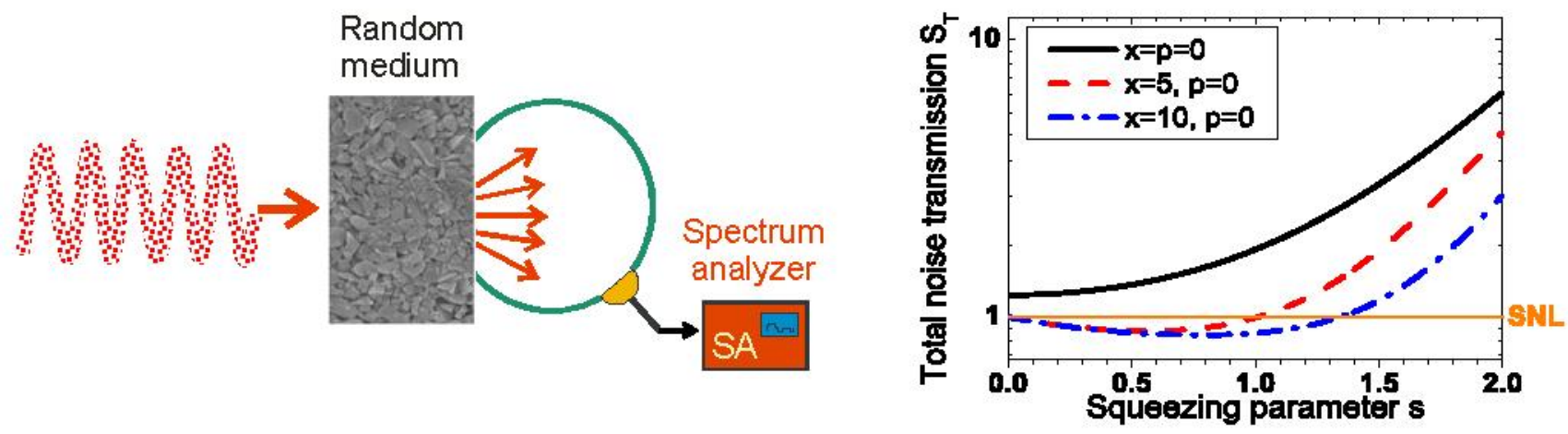

Figure 1. Left: Sketch of proposed experiment for measuring spatial quantum correlations. Light with squeezed quantum fluctuations is multiple scattered in a random medium. The noise of the total transmission is recorded with an integrating sphere and a spectrum analyzer. Right: Calculated noise of the total transmission as a function of squeezing parameter for three different quadrature amplitude squeezed states. SNL refers to the shot noise level that would be recorded with a coherent state of same intensity. Spatial quantum correlations are induced when the noise is below SNL.

[1] P. Lodahl, A.P. Mosk, and A. Lagendijk, "Spatial quantum correlations in multiple scattered light" Phys. Rev. Lett. 95, 173901 (2005).

[2] P. Lodahl, "Quantum noise frequency correlations of multiply scattered light", Opt. Lett. 31, 110 (2006). 